\title{
Direct observation of microcrack development in marble caused by thermal weathering
}

\author{
A. Luque $\cdot$ E. Ruiz-Agudo $\cdot$ G. Cultrone $\cdot$ \\ E. Sebastián $\cdot$ S. Siegesmund
}

Received: 18 November 2009/Accepted: 12 June 2010/Published online: 26 June 2010

(C) Springer-Verlag 2010

\begin{abstract}
One of the properties that makes marble such an excellent construction and ornamental material is its low porosity. It is very difficult for water or decay agents to penetrate the internal structure of materials with no or few pores, so enhancing the durability of these materials. However, environmental temperature fluctuations bring about significant physical changes in marbles that result in an increase in porosity, due to the appearance of new microcracks and the expansion of existing ones. These cracks offer new paths into the marble which make it easier for solutions containing pollutants to penetrate the material. Thermal expansion tests were performed on three different types of marble known as White, Tranco, and Yellow Macael (Almeria, Spain), after which an increase in porosity (from 17 to $73 \%$ depending on marble type) was observed, mainly due to crack formation. The structural changes occurring during thermal expansion tests were more significant in the case of White Macael samples, a fact that is not only related to its mineralogical composition but also to the morphology of the grains, grain boundaries
\end{abstract}

A. Luque $(\bowtie) \cdot$ E. Ruiz-Agudo · G. Cultrone · E. Sebastián Department of Mineralogy and Petrology, Faculty of Sciences, University of Granada, Avenida Fuentenueva s/n, 18002 Granada, Spain e-mail: analuque@ugr.es

E. Ruiz-Agudo

Institut für Mineralogie, University of Münster,

Corrensstr. 24, 48149 Münster, Germany

S. Siegesmund

Department of Structural Geology and Geodynamics,

Geoscience Centre, University of Göttingen,

Goldschmidtstr. 3, 37077 Göttingen, Germany and crystal size. Our research suggests that thermally weathered White Macael marble could be more susceptible to decay by other contaminant agents than Tranco or Yellow Macael. The use of hot-stage environmental scanning electron microscopy is proposed as a valid tool for observing, both in situ and at high magnification, changes in the fracture system of building stones induced by thermal stress.

Keywords Marble $\cdot$ Microcracks .

Thermal expansion anisotropy · Grain boundaries

\section{Introduction}

All building stones are exposed to weathering from the moment they are extracted from the quarry and used in the construction of a building. They undergo a series of structural and compositional changes in order to reach a new thermodynamic equilibrium (Mingarro 1996; AiresBarros 2000). Apart from these natural changes, building stones are also subject to different physical, chemical and biological weathering processes (Kühnel 2000) that may affect their durability as structural and ornamental materials (Mingarro 1996; Doehne 2002).

Because of its low porosity, marble has historically been considered a high quality material, and has been used in many important civil and religious buildings. Unfortunately, today there are numerous examples of historic marble buildings and sculptures which show weathering phenomena caused by thermal decay and the following action of soluble salts (e.g. the churches of San Marco, Santa Maria del Giglio and Santa Maria dei Miracoli in Venice, Michelangelo's David in Florence and the Courtyard of the Lions in the Alhambra of Granada). 
Environmental temperature fluctuations produce a series of initial physical and mechanical changes in marble stones (i.e. the first stage of weathering) that later enhance the effect of other weathering mechanisms (Battaglia et al. 1993; Siegesmund et al. 2000, 2007). Granular decohesion and bowing of marble due to temperature fluctuations have been reported in some cases, particularly when the stone is used in façades such as in Alvar Aalto's Finland Hall in Helsinki (Royer-Carfagni 1999), the Grande Arche de la Defense in Paris, the Lincoln Tower in Rochester (Cohen and Montiero 1991) and the Amoco building in Chicago (Logan et al. 1993). Kessler (1919) found that repeated heating may lead to permanent dilatation in marbles due to the formation of microcracks. Other authors (Bortz et al. 1988; Thomasen and Ewart 1984; Winkler 1996) have claimed that changes in moisture content may be responsible for the deformation of marbles. More recently, Koch and Siegesmund (2004) and Siegesmund et al. (2008) discovered that the bowing that occurs in some marbles is controlled by a combined effect of thermal cycling and the presence of moisture. However, it seems that the response of marble to temperature oscillations is mainly due to the thermal anisotropy of its mineralogical components: calcite and/or dolomite (Kleber 1959). The thermal expansion coefficient, $\alpha$, for these two minerals shows an extreme directional dependence, as a result of their different crystallographic directions. Parallel to the $c$-axis, both minerals have an $\alpha$ value of about $26 \times 10^{-6} \mathrm{~K}^{-1}$. However, parallel to the $a$-axis, dolomite shows a positive $\alpha$ value of about $6 \times 10^{-6} \mathrm{~K}^{-1}$, whereas calcite has a negative $\alpha$ value $\left(-6 \times 10^{-6} \mathrm{~K}^{-1}\right)$ (Grimm 1999; Weiss et al. 1999). For instance, in experiments carried out on marbles with different degrees of deterioration, porosity increased by $50 \%$ or more compared to the original material, when samples were subjected to thermal cycles with temperatures of over $50^{\circ} \mathrm{C}$ (Koch and Siegesmund 2004; Malaga-Starzec et al. 2002). The increase in porosity is the consequence of the effect produced by the marked anisotropy of calcite crystals. When temperature rises, the crystal expands in one direction (i.e. along the $c$-axis) and contracts perpendicularly to that direction. Such movements cause internal cleavages and the separation of crystals from their borders (Siegesmund et al. 2000).

Even though the thermal decay process affects dolomite and calcite marbles quite differently, the residual strain does not seem to be controlled exclusively by the composition, as there are other intrinsic factors that also determine their behaviour when subject to thermal expansion (Zeisig et al. 2002; Siegesmund et al. 2009). The rock fabric, which includes grain size, grain aspect ratio, grainshape preferred orientation, lattice preferred orientation (texture) and microcrack populations, plays an important role in how the marble behaves when subjected to thermal stress (Siegesmund et al. 2000; Royer-Carfagni 1999; Åkesson et al. 2006).

The main physical change produced by thermal oscillations is the change in the pore size distribution, even when the porosity is low (around 2\%) (Ruedrich et al. 2001; Siegesmund et al. 2008). The opening of new cleavage cracks between grain boundaries in marbles due to thermal changes increases the porosity of the stone and in most cases increases the number of large pores, and as a consequence, facilitates the penetration of water and solutions containing soluble salts or other pollutant agents into intergranular spaces (Zeisig et al. 2002; Ruiz-Agudo et al. 2008; Luque et al. 2009). This then causes different weathering phenomena such as salt crystallization, carbonate dissolution and/or the formation of calcium sulphate, which occur not only on the surface, but also inside the marble (Fassina et al. 2002; Simon and Snethlage 1993).

The aim of this paper is to characterize the changes in the porous system of three different types of marble (two calcitic marbles and one dolomitic) during thermal/ humidity tests. Textural modification will be monitored using ultrasounds, mercury intrusion porosimetry, $\mathrm{Ar}$ adsorption and hot-stage environmental scanning electron microscopy (ESEM). The use of this last technique is proposed as a novel approach to study, both in situ and at high magnification, how grain boundaries are affected by the residual strain generated by one thermal cycle. This tool can be used to evaluate textural modifications caused by thermal dilatation in dry conditions.

\section{Materials and methods}

\section{Marbles}

Three different varieties of marble were used, two of which were calcitic, White Macael (WM) and Tranco Macael (TM), and one dolomitic, Yellow Triana Macael (YM). These types of rocks are widely used as building materials, mainly for cladding, flooring and paving, and sometimes show signs of decay. All these marbles are quarried in the same geographic area, the "Comarca del Mármol" (the Marble County) in Almeria (Spain), although they are extracted from different quarries. The WM marble is quarried in Macael, while TM is quarried in LubrínZurgena and YM in Codbar. In geological terms, these three marbles are Late Triassic and belong to the NevadoFilabride Complex in the Sierra de los Filabres (Betic Internal Zone), which is the lowest tectonic unit of the Alboran Domain (Balanyá and García-Dueñas 1986): TM and YM are Nevado-Lubrín units and WM is a BédarMacael unit (Weijermars 1991). 
Methodology

Textural analysis of selected marbles was performed using an Olympus BX-60 polarized optical microscope (OM) coupled with digital microphotography (Olympus DP-10). The spatial and geometrical configuration of all the components of the three marbles in terms of fabric and microstructure was determined using the methodology proposed by Passichier and Trouw (1996), where normally the $Z$-axis is perpendicular to the foliation (Fig. 1). In order to obtain more information about the type of grain boundaries in each marble, we treated the negatives of optical micrographs using Photoshop ${ }^{\circledR}$ Elements ${ }^{\circledR} 2.0$ to provide the same brightness, contrast and gamma values for all the samples.

Due to their non-destructive nature, ultrasounds (US) are particularly useful for determining the physical properties of building stone. Measurements were performed using the transmission method and three measurements were taken for each spatial direction $(X, Y$ and $Z$ ). These data were used to infer information on the degree of compactness of marbles (a decrease in the velocity suggests the development of fissures) as well as on the textural anisotropy of marbles $(\Delta M$, in $\%)$, the value of which can be calculated as follows:

$\Delta M=\frac{1-\left(2 \times \mathrm{Vp}_{\text {min }}\right)}{\mathrm{Vp}_{\max }+\mathrm{Vp}_{\text {mid }}} \times 100$

where $\mathrm{Vp}_{\max }$ is the maximum, $\mathrm{Vp}_{\min }$ is the minimum and $\mathrm{Vp}_{\text {mid }}$ the medium value for ultrasonic wave velocity (Guyader and Denis 1986; Weiss et al. 2002b; Sáez-Pérez and Rodríguez-Gordillo 2009).

The flow of water into the stone pore system was determined by carrying out a water absorption test (WA). Real and apparent density and open porosity were measured by forced WA according to the UNE-EN 1936 (2007) standard. The modifications in the distribution of the pore

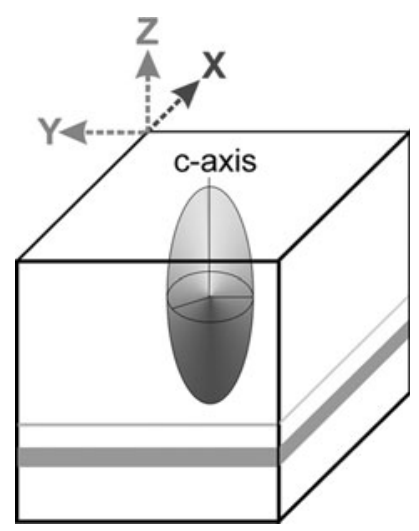

Fig. 1 Schematic representation of the marble samples with the reference axes positioned according to the foliation planes access size and the pore/fissure volume of the marbles before and after the thermal stress test were determined using a Micromeritics Autopore III 9410 mercury intrusion porosimeter (MIP), which is able to exert a maximum injection pressure of $414 \mathrm{MPa}$. Ar-sorption isotherms (GS) of sample fragments before and after the thermal salt tests were obtained at $77 \mathrm{~K}$ using a Micromeritics Tristar 3000 under continuous adsorption conditions. In samples with less than $5 \mathrm{~m}^{2} / \mathrm{g}$ surface area, Ar-sorption measurements are more realistic than $\mathrm{N}_{2}$ measurements that usually yield excessively high values and BET analysis was used to determine the total specific surface area (Brunauer et al. 1938). The BJH method (Barrett et al. 1951) was used to obtain pore size distribution curves, the pore volume and the mean pore size of the samples. The surface fractal dimension, $D_{\text {s }}$, was used to characterize surface roughness. The analysis of the gas sorption isotherm using a modified Frenkel-Halsey-Hill theory (Tang et al. 2003) allows the determination of surface fractal dimension from the slope $(A)$ of the plot of $\ln (V)$ versus $\ln \left[\ln \left(P / P_{0}\right)\right]$, where $V$ is the adsorbed volume of gas, and $P$ and $P_{0}$ are the actual and the condensation gas pressure. When surface tension (or capillary condensation) effects are important, the relationship between $A$ and $D_{\mathrm{s}}$ is $A=D_{\mathrm{s}}-3$. Capillary condensation is significant if $\delta=3(1+A)-2<0$. The pressure range and hence the thickness range of the adsorbed layer being studied was only around monolayer $(n=1-2)$ coverage to ensure that the determination of $D_{\mathrm{s}}$ was reliable (Tang et al. 2003).

The degree of thermal anisotropy of the marbles was evaluated by performing a thermal expansion test with respect to specific orientations $(X, Y$, and $Z$ ), according to pre-established axes. The test was carried out following the methodology proposed by Koch and Siegesmund (2004) in a chamber which allows the simultaneous analysis of six samples. 10 cycles were performed: 3 in dry conditions and 7 under wet conditions. In order to simulate temperature changes similar to those observed in buildings, each cycle follows the same temperature sequence of $20-90^{\circ} \mathrm{C}$ and back down to $20^{\circ} \mathrm{C}$ again over $15 \mathrm{~h}$ in dry conditions, and $17 \mathrm{~h}$ in wet conditions. The heating rate was $1 \% \mathrm{~min}$ to ensure the thermal equilibration of the specimens.

This technique allows us to calculate the thermal expansion coefficient $(\alpha)$ :

$\alpha=\frac{\Delta l}{l+\Delta T}$

which expresses the relative change in length $(l)$ or volume of the sample due to temperature changes $(\Delta T)$, as well as the thermal expansion $\left(\varepsilon_{\mathrm{rs}}=\Delta l_{\mathrm{rt}} / l_{\mathrm{r}}\right)$, which is the ratio of the change in length of the sample after cooling down to room temperature $\left(\Delta l_{\mathrm{rt}}\right)$ to the original sample length $\left(l_{\mathrm{r}}\right)$. The residual strain $(r)$ generated by the thermal expansion 
can also be obtained using this test. This parameter is a measurement of the irreversible damage that takes place in the sample once it returns to its initial (environmental) temperature (Kessler 1919).

An ESEM equipped with a heating stage was used to observe the formation of new cracks and the widening or closure of pre-existing ones during the following thermal cycle: $20-45-90-20^{\circ} \mathrm{C}$. The images were obtained on a FEI Quanta 400 ESEM, which operates at an accelerating voltage of $20 \mathrm{kV}$. During heating, the detector-sample distance was set to $\sim 12 \mathrm{~mm}$ and the ESEM chamber pressure was set at $\sim 2$ Torr water vapour. This water vapour pressure is equivalent to that of environmental air at $20^{\circ} \mathrm{C}$ and $15 \% \mathrm{RH}$. Each sample was heated at an average heating rate of between 3 and $5^{\circ} \mathrm{C} / \mathrm{min}$. A constant temperature was maintained during image acquisition, after $15 \mathrm{~min}$ as equilibration time.

The stone pore system (pore volume, pore size distribution, surface area and fractal dimension) was characterized using WA, MIP and GS (Xie et al. 1996; Pérez Bernal and Bello López 2000, 2001). Surface area and fractal dimension are important as they frequently indicate the presence of surface rugosity due to chemical weathering (Ruiz-Agudo et al. 2008).

\section{Results}

\section{Characterization of marbles}

Although samples are quarried in the same area, OM analysis showed important differences in the petrography of the three varieties of marble we tested (Table 1). White Macael, a calcitic marble, has a granoblastic micro-fabric with polygonal shapes, a grain size between 0.1 and $3 \mathrm{~mm}$ and straight to slightly curved grain boundaries (Fig. 2a). Microcracks and open cleavage planes are

Table 1 Mineralogical and petrographic features of the three marbles we tested

\begin{tabular}{llll}
\hline & White Macael & Tranco Macael & Yellow Macael \\
\hline \multicolumn{2}{l}{ Mineralogical composition } & $(\%)$ \\
Cc & $99 \pm 1$ & $98 \pm 2$ & $4 \pm 1$ \\
Dol & - & - & $95 \pm 3$ \\
Others & $1 \pm 0.01$ & $1 \pm 0.01$ & $1 \pm 0.1$ \\
Grain size $(\mathrm{mm})$ \\
Cc $\quad 0.1-3$ & $0.2-1.5$ & $0.5-1$ \\
Dol & - & - & $0.05-0.8$ \\
Others & $\leq 0.01$ & $\leq 0.01$ & $\leq 0.01$ \\
Texture & Granoblastic & Granoblastic & Granoblastic-seriate \\
\hline
\end{tabular}

Cc calcite, Dol dolomite straight and intra-particular. The micro-fabric in $X Y$-plane indicates a static recrystallization, in which grain boundaries become straighter and grains increase in size becoming hexagonal in shape (Luque et al. 2009). Tranco Macael, a white calcitic marble with a notable presence of irregular grey bands, shows a granoblastic micro-fabric with irregular shapes and grain sizes between 0.2 and $1 \mathrm{~mm}$ (up to $1.5 \mathrm{~mm}$ ). Grain boundaries are mainly "interlobate", although occasionally pseudo-linear unions were observed (Fig. 2b). Yellow Macael is a yellowish dolomitic marble which includes disperse calcite grains of residual origin and with preferred orientation and secondary calcite filling cracks and fractures. It shows a granoblastic micro-fabric with sizes of $0.05-0.8 \mathrm{~mm}$ for dolomite and $0.5-1 \mathrm{~mm}$ for calcite grains and it has interlobate grain boundaries. Fe-oxides, quartz, pyrite, muscovite and feldspars are also found as accessory minerals (Fig. 2c).

The main petrophysical properties of the quarried marbles are shown in Table 2. According to Weiss et al. (2002b), the propagation velocity of ultrasonic waves (Vp) within the stone matrix can determine the intrinsic and extrinsic properties of marbles, and therefore, the structural anisotropy of these crystalline materials, as well as the existence of microcracks when the $\mathrm{Vp}$ values are measured in dry and saturated conditions (Siegesmund et al. 1999, 2009). Taking into account the $\mathrm{Vp}$ values measured by Dandekar (1968) in a single calcite crystal $\left(\mathrm{Vp}_{\max }=\right.$ $7,730 \mathrm{~m} / \mathrm{s}$ and $\mathrm{Vp}_{\min }=5,710 \mathrm{~m} / \mathrm{s}$ ) and a single dolomite crystal $\left(\mathrm{Vp}_{\max }=8,450 \mathrm{~m} / \mathrm{s}\right.$ and $\left.\mathrm{V} \mathrm{p}_{\min }=6,280 \mathrm{~m} / \mathrm{s}\right)$, we can see that all three marbles types always have lower values, but the same tendency of single calcite and dolomite crystals. Table 2 shows the dry and water-saturated values, and the anisotropy in the three cases.

This suggests that the three types of marble show some degree of textural preferential orientation, when the $c$-axis (minimum values in the three marbles) is parallel to the $z$-axis established in our coordinate system. Moreover, microcracks, whose existence was confirmed by comparing dry and water-saturated values, have certain directionality, perpendicular to the $c$-axis (maximum difference between $\mathrm{Vp}_{\text {dry }}$ and $\mathrm{Vp}_{\mathrm{sat}}$ ).

The existence of pores (or fissures), of which there are generally very few, is confirmed by the porosity values obtained by water absorption, mercury intrusion porosimetry and gas adsorption tests in fresh marbles (Table 2).

$D_{\mathrm{f}}$ and $D_{\mathrm{s}}$ parameters are consistent with the fissure morphology and the degree of fissure surface roughness observed under OM. Therefore, we can affirm that WM has a fissure system with rectilinear trend morphology $\left(D_{\mathrm{f}}=2.77\right)$ and high surface roughness $\left(D_{\mathrm{s}}=2.88\right)$, YM has more irregular morphology fissures $\left(D_{\mathrm{f}}=2.79\right)$ and low surface roughness $\left(D_{\mathrm{s}}=2.68\right)$ and TM has 
Table 2 Petrophysical characterization of White Macael, Tranco Macael and Yellow Macael (fresh samples)

\begin{tabular}{|c|c|c|c|c|c|c|c|c|c|c|c|c|}
\hline & \multicolumn{4}{|c|}{ White Macael } & \multicolumn{4}{|c|}{ Tranco Macael } & \multicolumn{4}{|c|}{ Yellow Macael } \\
\hline & $x$ & $y$ & $z$ & $\Delta M(\%)$ & $x$ & $y$ & $z$ & $\Delta M(\%)$ & $x$ & $y$ & $z$ & $\Delta M(\%)$ \\
\hline \multicolumn{13}{|l|}{ Ultrasound tests, Vp (m/s) } \\
\hline Dry samples & 5.885 & 5.756 & 5.058 & 13.10 & 6.210 & 5.678 & 5.387 & 9.37 & 6.597 & 6.573 & 5.165 & 21.56 \\
\hline Water-saturated samples & 6.405 & 6.386 & 6.246 & 2.34 & 6.589 & 6.253 & 6.073 & 5.42 & 7.452 & 7.304 & 6.816 & 7.62 \\
\hline \multicolumn{13}{|l|}{ (a) } \\
\hline Water-access porosity, $\Phi$ (vol.\%) & 0.41 & & & & 0.35 & & & & 0.94 & & & \\
\hline $\begin{array}{l}\text { Real density by water absorption, } \\
\rho_{\text {rock }}\left(\mathrm{g} / \mathrm{cm}^{3}\right)\end{array}$ & 2.70 & & & & 2.73 & & & & 2.92 & & & \\
\hline \multicolumn{13}{|l|}{ (b) } \\
\hline Porosity, $P(\%)$ & 1.76 & & & & 0.75 & & & & 2.42 & & & \\
\hline Real density, $\rho_{\text {rock }}\left(\mathrm{g} / \mathrm{cm}^{3}\right)$ & 2.72 & & & & 2.75 & & & & 2.92 & & & \\
\hline Surface area, $\mathrm{SA}\left(\mathrm{m}^{2} / \mathrm{g}\right)$ & 0.185 & & & & 0.258 & & & & 0.754 & & & \\
\hline $\begin{array}{l}\text { Fractal dimension calculated } \\
\text { using MIP data, } D_{\mathrm{f}}\end{array}$ & 2.77 & & & & 2.87 & & & & 2.79 & & & \\
\hline \multicolumn{13}{|l|}{ (c) } \\
\hline Pore volume, $\mathrm{P}$ vol. $\left(\mathrm{cm}^{3} / \mathrm{g}\right)$ & 0.00000 & & & & 0.00021 & & & & 0.00022 & & & \\
\hline Surface area, SA BET $\left(\mathrm{m}^{2} / \mathrm{g}\right)$ & 0.198 & & & & 0.316 & & & & 0.347 & & & \\
\hline $\begin{array}{l}\text { Fractal dimension calculated } \\
\text { using GS data, } D_{\mathrm{s}}\end{array}$ & 2.88 & & & & 2.82 & & & & 2.68 & & & \\
\hline
\end{tabular}

Table 3 Thermal parameters of White Macael, Tranco Macael and Yellow Macael marbles

\begin{tabular}{|c|c|c|c|c|c|c|c|c|c|c|c|c|}
\hline & \multicolumn{4}{|c|}{ White Macael } & \multicolumn{4}{|c|}{ Tranco Macael } & \multicolumn{4}{|c|}{ Yellow Macael } \\
\hline & $X$ & $Y$ & $Z$ & $\Delta(\%)$ & $X$ & $Y$ & $Z$ & $\Delta(\%)$ & $X$ & $Y$ & $Z$ & $\Delta(\%)$ \\
\hline$\alpha\left(10^{-6} \mathrm{~K}^{-1}\right)$ & 16.67 & 9.52 & 23.97 & 53.15 & 4.66 & 10.69 & 13.92 & 62.13 & 12.91 & 13.34 & 16.57 & 13.67 \\
\hline$\varepsilon_{\mathrm{rs}}(\mathrm{mm} / \mathrm{m})$ & 0.86 & 0.43 & 1.31 & 60.37 & 0.18 & 0.54 & 0.72 & 71.43 & 0.66 & 0.68 & 0.85 & 13.73 \\
\hline$r(\mathrm{~mm} / \mathrm{m})$ & 0.31 & 0.09 & 0.29 & 69.80 & 0.08 & 0.06 & 0.13 & 42.57 & 0.01 & 0.01 & 0.07 & 74.97 \\
\hline$r^{*}(\mathrm{~mm} / \mathrm{m})$ & 0.6423 & 0.2789 & 0.7723 & 60.57 & 0.3229 & 0.4843 & 0.5101 & 35.05 & 0.1695 & 0.1222 & 0.4677 & 61.63 \\
\hline
\end{tabular}

$\alpha$ thermal dilatation coefficient, $\varepsilon_{\mathrm{rs}}$ thermal expansion, $r$ residual strain after first thermal dry cycle, $r^{*}$ residual strain after ten thermal cycles $(3$ in dry conditions and 7 in wet conditions) $(\mathrm{mm} / \mathrm{m}), \Delta$ anisotropy determined in each marble for each parameter

interlobate fissures $\left(D_{\mathrm{f}}=2.87\right)$ and high surface roughness $\left(D_{\mathrm{s}}=2.82\right)$.

These values give us some idea of the pore structure at different scales; in particular, $D_{\mathrm{s}}$ can be considered as an index of the pore structure at the nanoscale, i.e. the rugosity of the pore surface.

\section{Thermal expansion tests}

Table 3 shows the thermal expansion coefficient $(\alpha$, in $\left.10^{-6} \mathrm{~K}^{-1}\right)$, thermal expansion $\left(\varepsilon_{\mathrm{rs}}\right.$, in $\left.\mathrm{mm} / \mathrm{m}\right)$ and residual strain $(r$, in $\mathrm{mm} / \mathrm{m})$ values obtained along the $X, Y$ and $Z$ perpendicular directions for each marble during the first thermal dry cycle $\left(20-90-20^{\circ} \mathrm{C}\right)$, as well as the degree of anisotropy of the marbles. WM and YM samples show the highest $\alpha$ and $\varepsilon_{\mathrm{rs}}$ values. However, in the three marbles, the highest value for these two parameters is observed along the $Z$-axis, which may indicate a preferred orientation of carbonates along this direction. Moreover, if we take into account the anisotropy values of each parameter $(\Delta \alpha$ and $\Delta \varepsilon)$ in the three marbles, we can see that the anisotropy in WM $(\Delta \alpha=53.15 \% ; \Delta \varepsilon=60.37 \%)$ and $\mathrm{TM}(\Delta \alpha=$ $62.13 \% ; \Delta \varepsilon=71.43 \%)$ marbles is much higher than in YM marble $(\Delta \alpha=13.67 \% ; \Delta \varepsilon=13.73 \%)$, which indicates that calcite causes a stronger anisotropy than dolomite. These values only reflect the behaviour of the marbles during the first dry cycle and they tend to remain constant during the following two dry cycles (Fig. 3). However, when these cycles are performed in wet conditions, $\alpha$ and $\varepsilon_{\mathrm{rs}}$ values show a significant increase. This is mainly due to the effect of water and the pressure it exerts at high temperature $\left(90^{\circ} \mathrm{C}\right)$, when it is retained in the grain boundaries of the marble samples (Winkler 1994). Finally, after 10 thermal cycles ( 3 dry cycles and 7 wet cycles) have 

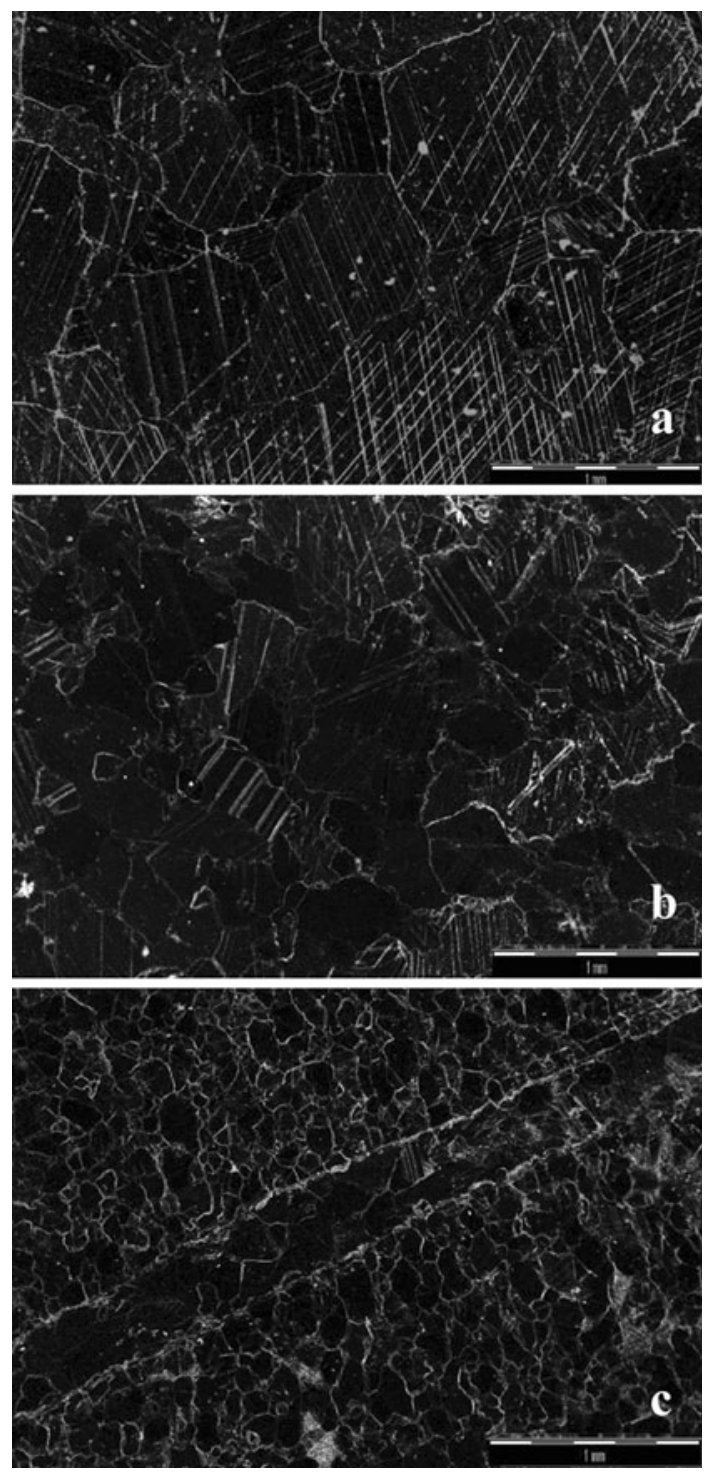

Fig. 2 Optical microscopy image of a White Macael, b Tranco Macael and c Yellow Macael marble micro-fabric

been carried out, the residual strain $(r)$ is the main parameter that evaluates the damage induced in the three types of marble. Although $r$ values are very different in the three marbles, all of them increase as the number of cycles increases. The increase follows this order: YM $(X=0.01 \mathrm{~mm} / \mathrm{m} ; \quad Y=0.01 \mathrm{~mm} / \mathrm{m} ; \quad Z=0.07 \mathrm{~mm} / \mathrm{m})<$ TM $(X=0.08 \mathrm{~mm} / \mathrm{m} ; Y=0.06 \mathrm{~mm} / \mathrm{m} ; Z=0.13 \mathrm{~mm} / \mathrm{m})$ $<$ WM $(X=0.31 \mathrm{~mm} / \mathrm{m} ; Y=0.09 \mathrm{~mm} / \mathrm{m} ; Z=0.29 \mathrm{~mm} /$ $\mathrm{m})$ after the three first dry cycles; YM $(X=0.17 \mathrm{~mm} / \mathrm{m}$; $Y=0.12 \mathrm{~mm} / \mathrm{m} ; Z=0.47 \mathrm{~mm} / \mathrm{m})<\mathrm{TM}(X=0.32 \mathrm{~mm} / \mathrm{m}$; $Y=0.48 \mathrm{~mm} / \mathrm{m} ; Z=0.51 \mathrm{~mm} / \mathrm{m})<\mathrm{WM}(X=0.64 \mathrm{~mm} / \mathrm{m}$; $Y=0.28 \mathrm{~mm} / \mathrm{m} ; Z=0.77 \mathrm{~mm} / \mathrm{m})$ after the following seven wet cycles (Fig. 4).

To quantify the damage induced by the thermal expansion test in each marble, the main petrophysical properties (compactness and porosity) were measured again in marble

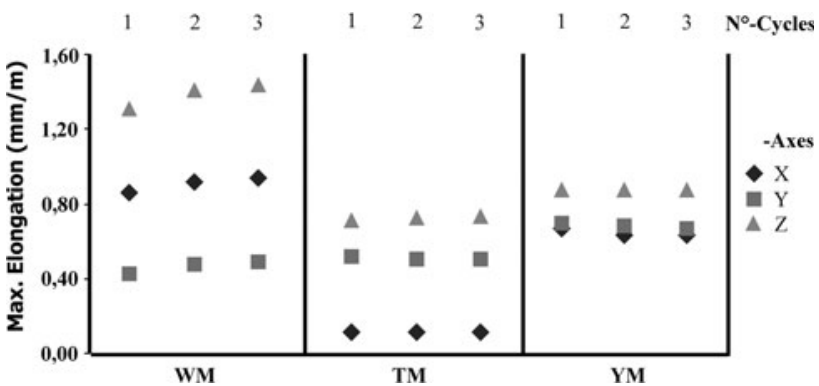

Fig. 3 Maximum elongation of marbles heated up to $90^{\circ} \mathrm{C}$ during the first three consecutive dry cycles along the three perpendicular directions $(X, Y$ and $Z$ ). $W M$ White Macael, $T M$ Tranco Macael, $Y M$ Yellow Macael

core samples. The new values are shown in Table 4. The decrease in $\mathrm{Vp}$ values was higher in WM marble (between 37 and 55\%) compared to YM (between 29 and 45\%) and TM (between 19 and 25\%), and this may be related to the damage induced by thermal changes, leading to an important loss of compactness (Köhler 1991; Siegesmund et al. 2000; Weiss et al. 2002a). By the end of the tests, porosity had increased in all three types of marble. The pore size distribution had also changed, as was confirmed by the values for fractal dimension, $D_{\mathrm{f}}$ and $D_{\mathrm{s}}$.

Although an increase in porosity was observed in all three marble types, they each underwent different changes in pore size distribution. Figure 5 shows the pore size distribution of the samples before and after thermal expansion tests. The number of pores of less than $1 \mu \mathrm{m}$ increased in TM and YM marbles; however, WM marble experienced a substantial increase in the number of pores of around $1 \mu \mathrm{m}$ and above $30 \mu \mathrm{m}$, with no significant change in the pore volume below $1 \mu \mathrm{m}$. This coincides with the observed magnitude of $D_{\mathrm{s}}$ for the three marbles. The main changes in the WM pore system occur in pores of $>1 \mu \mathrm{m}$, which cannot be quantified by GS; and this is why the $D_{\mathrm{s}}$ value remains relatively unchanged compared to that for the fresh sample $\left(\Delta D_{\mathrm{s}}=1.4 \%\right)$. On the contrary, TM and YM samples show significant modifications in the pore system below $1 \mu \mathrm{m}$, which is reflected by a higher relative decrease of the fractal dimension determined using GS ( $\Delta D_{\mathrm{s}}$ is 5.3 and $4.5 \%$ for $\mathrm{TM}$ and $\mathrm{YM}$, respectively).

\section{Hot-stage ESEM}

The use of hot-stage ESEM allowed a direct observation of the evolution of the marble microcracks system during thermal cycles.

ESEM images were obtained using the same temperature range used in the thermal expansion test (from $20^{\circ} \mathrm{C}$ to 45,90 and again to $20^{\circ} \mathrm{C}$ ). At $20^{\circ} \mathrm{C}$ (Fig. 6a), no modifications were observed, but when the temperature rose to $45^{\circ} \mathrm{C}$ the samples started to suffer textural modifications, 
Table 4 Petrophysical characterization of White Macael, Tranco Macael and Yellow Macael after the thermal expansion tests

\begin{tabular}{|c|c|c|c|c|c|c|c|c|c|c|c|c|}
\hline & \multicolumn{4}{|c|}{ White Maacel } & \multicolumn{4}{|c|}{ Tranco Macael } & \multicolumn{4}{|c|}{ Yellow Macael } \\
\hline & $x$ & $y$ & $z$ & $\Delta M(\%)$ & $x$ & $y$ & $z$ & $\Delta M(\%)$ & $x$ & $y$ & $z$ & $\Delta M(\%)$ \\
\hline \multicolumn{13}{|l|}{ Ultrasound test, $\mathrm{Vp}(\mathrm{m} / \mathrm{s})$} \\
\hline Dry samples & 2.647 & 3.625 & 2.794 & 17.53 & 5.010 & 4.550 & 4.057 & 15.13 & 4.714 & 4.567 & 2.866 & 38.24 \\
\hline Water-saturated samples & 5.985 & 6.214 & 5.964 & 2.22 & 6.148 & 6.023 & 5.577 & 8.36 & 6.824 & 6.965 & 6.367 & 7.65 \\
\hline $\begin{array}{l}\text { Difference between fresh and altered } \\
\text { dry samples }(\%)\end{array}$ & 55 & 37 & 45 & 26 & 19 & 20 & 25 & 13 & 29 & 31 & 45 & 24 \\
\hline \multicolumn{13}{|l|}{ (a) } \\
\hline Water-access porosity, $\Phi($ vol.\%) & 0.67 & & & & 0.48 & & & & 0.92 & & & \\
\hline $\begin{array}{l}\text { Real density by water absorption, } \\
\rho_{\text {rock }}\left(\mathrm{g} / \mathrm{cm}^{3}\right)\end{array}$ & 2.71 & & & & 2.74 & & & & 2.93 & & & \\
\hline \multicolumn{13}{|l|}{ (b) } \\
\hline Porosity, $P(\%)$ & 6.63 & & & & 1.21 & & & & 2.91 & & & \\
\hline Real density, $\rho_{\text {rock }}\left(\mathrm{g} / \mathrm{cm}^{3}\right)$ & 2.72 & & & & 2.70 & & & & 2.92 & & & \\
\hline Surface area, $\mathrm{SA}\left(\mathrm{m}^{2} / \mathrm{g}\right)$ & 1.342 & & & & 0.573 & & & & 0.449 & & & \\
\hline $\begin{array}{l}\text { Fractal dimension calculated using } \\
\text { MIP data, } D_{\mathrm{f}}\end{array}$ & 2.69 & & & & 2.92 & & & & 2.94 & & & \\
\hline \multicolumn{13}{|l|}{ (c) } \\
\hline Pore volume, $\mathrm{P}$ vol. $\left(\mathrm{cm}^{3} / \mathrm{g}\right)$ & \multicolumn{4}{|c|}{0.00005} & \multicolumn{4}{|c|}{0.000111} & \multicolumn{4}{|c|}{0.00020} \\
\hline Surface area, SA BET $\left(\mathrm{m}^{2} / \mathrm{g}\right)$ & \multicolumn{4}{|c|}{0.116} & \multicolumn{4}{|l|}{0.143} & \multicolumn{4}{|c|}{0.205} \\
\hline $\begin{array}{l}\text { Fractal dimension calculated using } \\
\text { GS data, } D_{\mathrm{s}}\end{array}$ & \multicolumn{4}{|l|}{2.84} & \multicolumn{4}{|l|}{2.67} & \multicolumn{4}{|l|}{2.56} \\
\hline
\end{tabular}
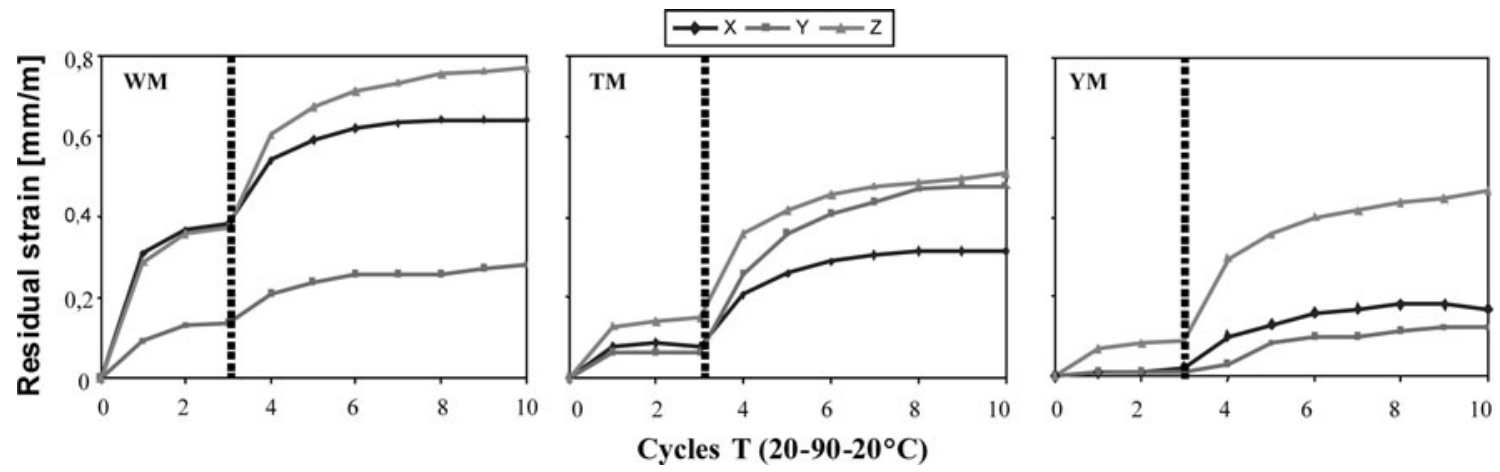

Fig. 4 Residual strain versus number of cycles for White Macael (WM), Tranco Macael (TM) and Yellow Macael (YM) marbles during thermal expansion tests ( 3 dry cycles and 7 wet cycles). The dotted line divides dry (left) from wet (right) cycles

which were further enhanced when the temperature reached $90^{\circ} \mathrm{C}$. Nevertheless, although grain boundaries in the three marbles were observed to seal when the temperature was reduced back to $20^{\circ} \mathrm{C}$, none of them returned to their initial state. In the case of the WM marble, slight textural changes were detected at $45^{\circ} \mathrm{C}$ (Fig. 6b); at this temperature, the space between the calcite grains began to widen. This change was better observed when the temperature was increased to $90^{\circ} \mathrm{C}$ (Fig. 6c), and microcracks that were just a few microns wide $(\sim 1 \mu \mathrm{m})$ but over $50 \mu \mathrm{m}$ in length appeared. When the marble returned to its starting temperature $\left(20^{\circ} \mathrm{C}\right)$, the separation between the crystals decreased $(\sim 0.5 \mu \mathrm{m})$ but the length remained the same, allowing connectivity between microcracks
(Fig. 6d). The behaviour of TM marble during the thermal cycle in the ESEM chamber was considerably different. Slight changes were detected in the marble crack and fissure system when the temperature rose to $90^{\circ} \mathrm{C}$; at the end of the first thermal cycle, when the marble went back to $20^{\circ} \mathrm{C}$, cracks and fissures had sealed and were almost invisible (Fig. 7a-d) and connection along the grain boundaries was lost. Finally, in spite of the different mineralogical composition of YM marble, significant alterations also occurred in its fissure system when samples were subjected to temperature fluctuations. This marble behaved in the opposite manner to the TM marble, as crack opening reached a maximum when the sample temperature fell back to $20^{\circ} \mathrm{C}$ after reaching $90^{\circ} \mathrm{C}$. At this temperature $\left(20^{\circ} \mathrm{C}\right)$, 


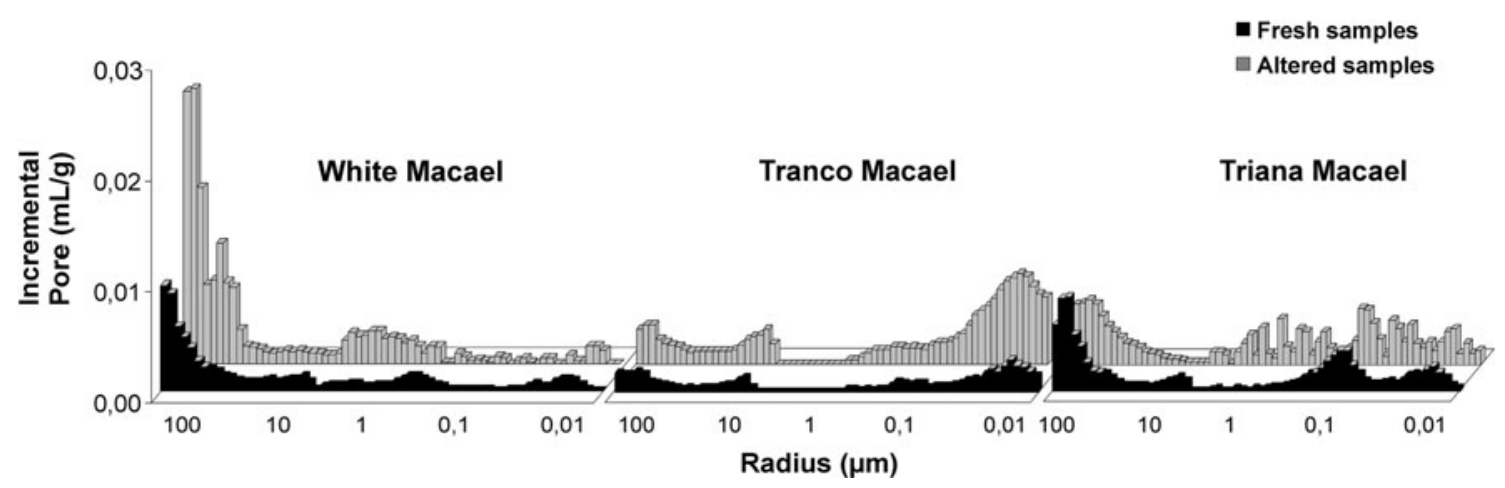

Fig. 5 Pore size distribution plots for the three marbles tested, in fresh and altered samples, after the thermal expansion tests

Fig. 6 ESEM images of White Macael marble surfaces during thermal cycles in the microscope chamber. Cracks are observed to widen as temperature is increased (a $20^{\circ} \mathrm{C}, \mathbf{b} 45^{\circ} \mathrm{C}, \mathbf{c ~} 90^{\circ} \mathrm{C}$, d $20^{\circ} \mathrm{C}$ ), and are still visible once the sample returns to $20^{\circ} \mathrm{C}$ (d). Black arrows indicate the position of microcracks
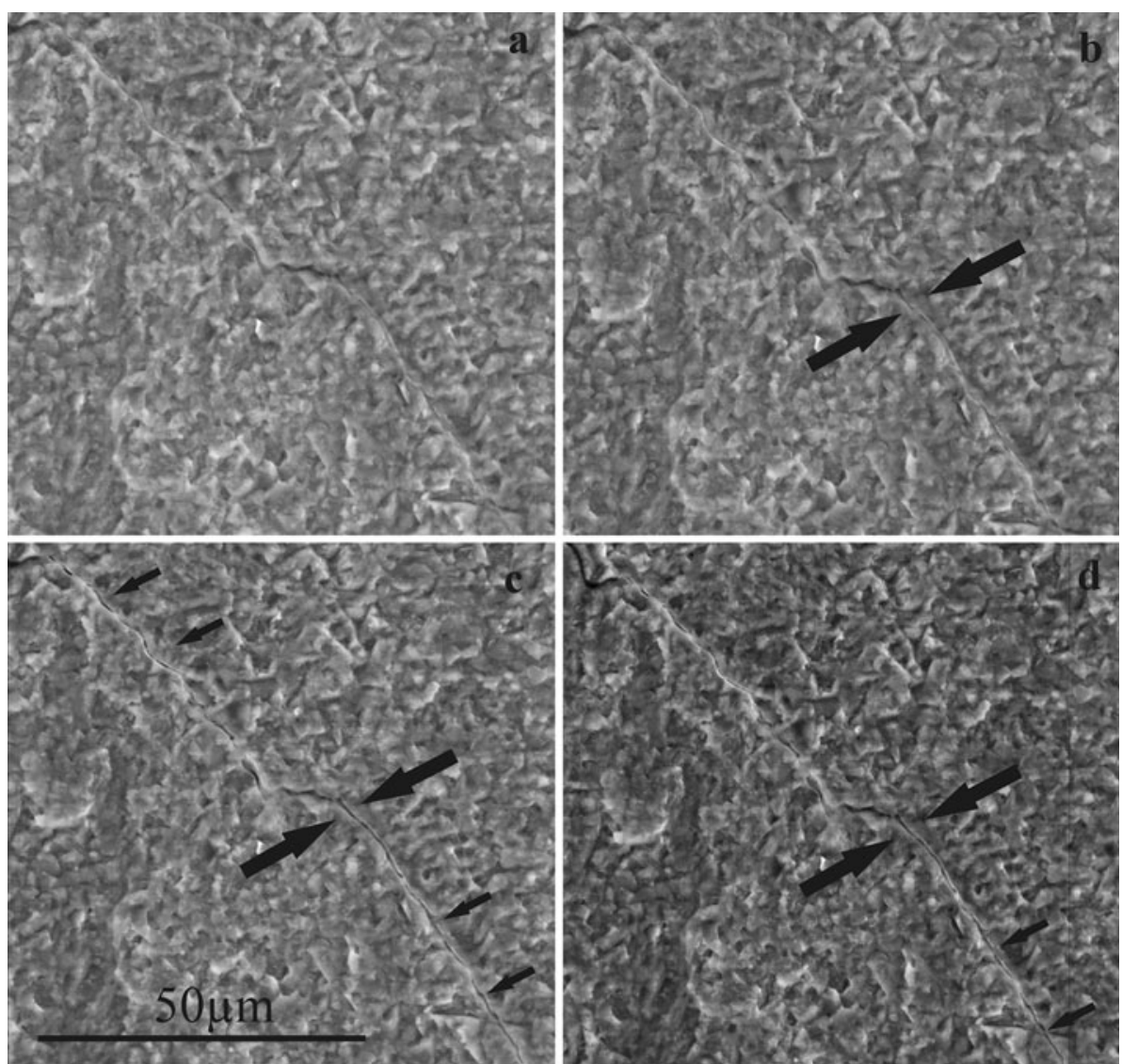

the development of microcracks was evident (Fig. 8a-d). These cracks were large $(\sim 2 \mu \mathrm{m} \times 10 \mu \mathrm{m})$, but there was less connection between the grains than with WM.

\section{Discussion and conclusions}

The results of our research have shown that numerous factors contribute to marble weathering due to thermal changes. All of these results indicate that marble mineralogical composition, fabric, grain size and shape, and the type of union between crystals are the main factors influencing marble behaviour towards thermal changes.

Four aspects of the hot-stage ESEM test should be considered. The first two are based on the technique we have used; the other two depend on the finite element models applied to the expansion and development of microcracks in marbles with the increase of temperature (Weiss et al. 2002a, 2003).

1. This test confirms that the main decay agent in marble is thermal change, due to the anisotropic expansion of 
Fig. 7 ESEM images of Tranco Macael marble surfaces during thermal cycles in the microscope chamber. Slight changes in the crack system are observed during the temperature rise $\left(\mathbf{a} 20^{\circ} \mathrm{C}, \mathbf{b} 45^{\circ} \mathrm{C}, \mathbf{c} 90^{\circ} \mathrm{C}\right.$, d $20^{\circ} \mathrm{C}$ ); however, when the sample returns to $20^{\circ} \mathrm{C}$, the fractures seal up (d). Black arrows indicate the position of microcracks
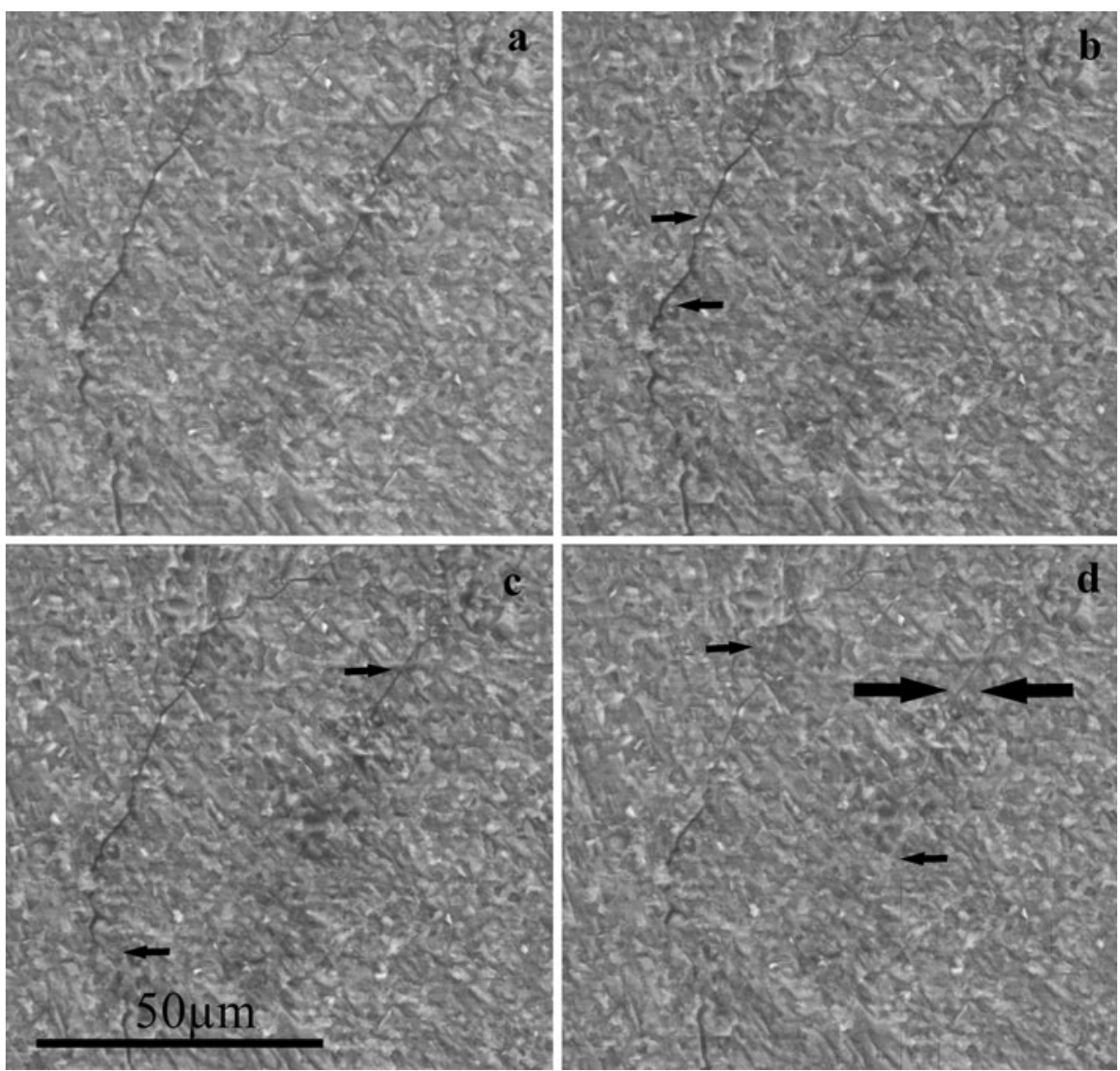

calcite and dolomite crystals. Thermal expansion harms calcite marbles more than dolomite marbles and this effect is even more dangerous if the marbles have straight grain boundaries.

2. The ESEM technique allows us to view directly the formation and propagation of microcracks generated by thermal stress in marbles, and, thus gain a better knowledge of the kinematics displayed by the crystals and the grain boundaries during heating.

3. From the images obtained during the thermal test in all marbles, the greatest expansion and the largest separation between grain boundaries occur at the highest temperature selected in this work $\left(90^{\circ} \mathrm{C}\right)$. The microcracks are intergranular and/or transgranular.

4. It is important to bear in mind that, once microcracks have developed, the elastic energy is mitigated and the largest concentration of residual elastic energy moves toward the boundaries between the grains. When the marble returns to its initial temperature at the end of a heating cycle $\left(20^{\circ} \mathrm{C}\right)$, most of the edges of the carbonate grains along the $x z$-plane are brighter (see Figs. 6, 7, 8), which may indicate a higher concentration of electrical charge produced in this area by increased residual energy.
5. The development of microcracks obtained with this experiment is consistent with the porosity observed using MIP. In the case of WM, the microcracks are bigger than in TM and YM. This justifies our MIP results for this marble, which showed an excessive pore volume (over 6\%) and a range of pores of over $10 \mu \mathrm{m}$. We can, therefore, also conclude that a large grain size with straight grain boundaries helps the formation of microcracks of great length and connectivity.

These four aspects show that the hot-stage ESEM test is an effective technique for directly observing the different mechanisms of expansion-contraction and the distribution of microcracks generated during the thermal change in different types of marble.

From the results of the thermal expansion tests and the in situ observations during hot-stage ESEM simulation, it is clear that the three selected marbles, regardless of their mineralogy, fabric or texture, undergo significant changes in their crack and fissure systems.

If we compare the petrographic properties of fresh and weathered samples, it can be inferred that well-developed crystal shapes, larger grain size and linear grain 
Fig. 8 ESEM images of Yellow Macael marble surfaces during thermal cycles in the microscope chamber. Widening of cracks is observed as the temperature $\left(\mathbf{a} 20^{\circ} \mathrm{C}, \mathbf{b} 45^{\circ} \mathrm{C}\right.$, c $90^{\circ} \mathrm{C}, \mathbf{d ~} 20^{\circ} \mathrm{C}$ ) is increased, and is still visible once the sample returns to $20^{\circ} \mathrm{C}$ (d). Black arrows indicate the position of microcracks
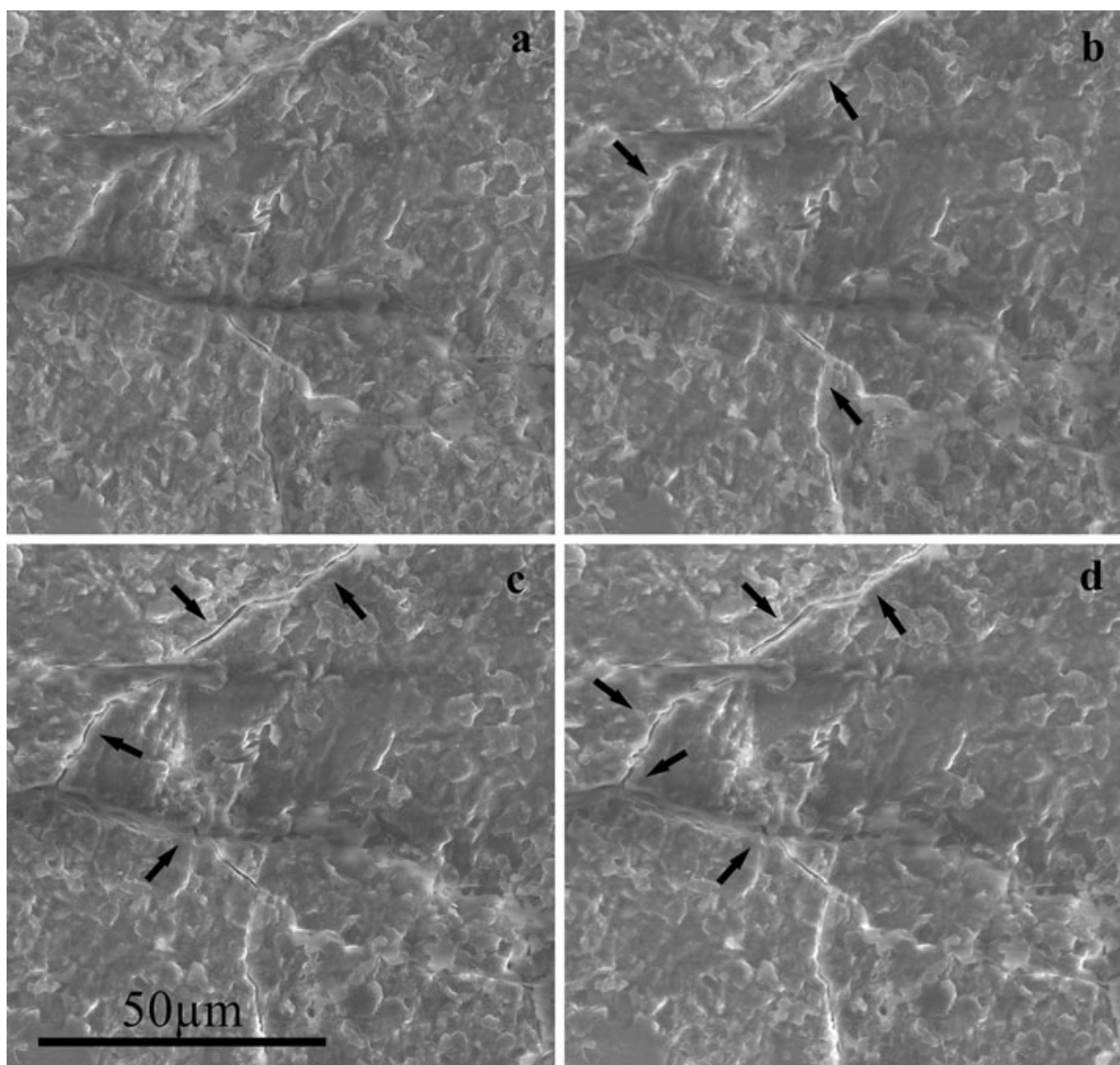

boundaries are the main properties responsible for the dramatic effects of environmental thermal oscillations on the pore system of the marbles and, as a consequence, in their potential susceptibility to weathering. In the case of the WM marble, its strong textural anisotropy and high degree of thermal expansion are the main parameters that determine its response to thermal changes. Its bigger crystal size (compared to TM and YM samples) and its simple, almost linear grain boundaries may result in a high degree of thermal expansion and the development of microcracks. As thermal expansion is a linear property and the induced elongation is going to be proportional to the initial length of the axes under consideration, it seems reasonable to assume that the highest elongation is going to take place in the marble with the biggest grain size (WM) and, vice versa, the lowest elongation will occur in marbles with smaller grain sizes (TM and YM). This may result in higher impact energies when bigger crystals interact than when smaller grains do. On the other hand, as has already been mentioned, the type of grain boundaries is an important factor which determines the behaviour of marbles during thermal tests. Simple grain boundaries indicate lower binding energy between them and interlobate-type unions reflect higher binding energy between grains; thus, crystal separation will occur more easily in WM marble than in TM and YM marbles, which show tortuous boundaries and a higher binding energy. This is important when considering the results of the study of the porous system by MIP and GS, as these tests help to predict the behaviour of marbles that are thermally altered when they come into contact with soluble salts or other contaminant agents. The most pronounced modification of the stone porous system after the thermal expansion tests [in terms of porosity and pore size distribution, as well as other parameters such as compactness (inferred from the value of the propagation velocity of ultrasound waves), surface area or fractal dimension] was observed for WM marble. These changes can be explained by the formation of new linear fractures ( $\sim 1 \mu \mathrm{m}$ in size) or the widening of pre-existing ones $(\sim 10-100 \mu \mathrm{m})$. As explained earlier, even though these openings are large, they are consistent with those produced (during a single cycle) in the hot-stage attached to the ESEM. The opening of new linear fractures exposes new, flat surfaces that result in lower fractal dimension compared to fresh samples. In general, these modifications may enhance the weathering action of dissolved contaminants such as soluble salts or sulphuric acid, 
mainly due to both increased accessibility of such pollutants to the stone matrix and the increase in the volume of material affected by decay agents.

Another interesting aspect is that the marbles we studied exhibit different mechanisms of grain rearrangement when they return to $20^{\circ} \mathrm{C}$ after a thermal cycle. ESEM image sequences confirm such differences. Whereas in the case of TM marble calcite grains reorganize themselves resulting in the closure of cracks, in WM and YM marbles the cracks that open or widen during thermal cycles remain visible after the test has finished. Differences in crystal shape and size, and overall, grain size distribution may explain the mechanisms observed in each marble. Equidimensional and homogeneously sized crystals (such as those observed in WM and YM samples) cannot easily rearrange, which means that cracks remain open. Non-equidimensional crystals with a polydisperse size distribution can be reorganized in a more compact way, thus resulting in the closure of cracks and fissures. This may also help to interpret the residual strain values, which are higher in the case of TM marble and the changes in the rate of ultrasound wave propagation and porosity after thermal tests, both of which indicate that TM samples show the smallest degree of alteration when subjected to thermal oscillations. We can, therefore, deduce that in TM marble a temperature rise results in length changes, but once the temperature falls back to its original level, grain reorganization leads to crack closing, which is in turn reflected in the small change in porosity and pore size distribution.

We are aware that the duration of the test is limited (10 cycles in total) and that the test does not exactly reproduce the real weathering process that occurs when a material is exposed to temperature changes for decades or centuries. However, it is likely that the structural modifications will be more pronounced as the number of cycles is increased. This work offers an accurate representation of the physical processes taking place during exposure to environmental temperature oscillations, and also allows us to compare different materials in terms of their response to thermal stress. The results of this work may contribute to a better understanding of the processes that cause the weathering of marbles used as building or ornamental materials. In particular, the environmental temperature oscillations that generally affect marbles result in changes in the structure of the pore system (i.e. a first stage of decay) of the stones that enhances or facilitates the potential action of other contaminant agents.

Acknowledgments This research was financed by Research Project FQM 1635, the Integrated Action HA 2007-0012, the European Commission VIth Framework Program (Contract no. SSP1-CT-2003501571) and Research Group RNM-179 (Junta de Andalucía, Spain). We thank I. Sanchez-Almazo (CEAMA, Junta de AndalucíaUniversidad de Granada) for her assistance with ESEM analysis.

\section{References}

Aires-Barros L (2000) Modes and mechanisms of rock weathering. Protection and conservation of the cultural heritage of the Mediterranean cities. In: Proceedings of the 5th international symposium on the conservation of monuments in the Mediterranean Basin, Seville, Spain, pp 3-6

Åkesson U, Lindqvist JE, Schouenborg B, Grelk B (2006) Relationship between microstructure and bowing properties of calcite marble claddings. Bull Eng Geol Environ 65:73-79

Balanyá JC, García-Dueñas V (1986) Grandes fallas de contracción y de extensión implicadas en el contacto entre los dominios de Alborán y Sudibérico en el Arco de Gibraltar. Geogaceta 1:19-21

Barrett EP, Joyner LS, Halenda PPJ (1951) The determination of pore volume and area distributions in porous substances. I. Computations from nitrogen isotherms. J Am Chem Soc 73:373-380

Battaglia S, Franzini M, Mango F (1993) High sensitivity apparatus for measuring linear thermal expansion: preliminary results on the response of marbles. Il Nuovo Cimiento 16:453-461

Bortz SA, Erlin B, Monk CB (1988) Some field problems with thin veneer building stones, new stone technology, design and construction for exterior wall systems. American Society for Testing and Materials, Philadelphia, pp 11-31

Brunauer S, Emmett PH, Teller EJ (1938) Adsorption of gases in multimolecular layers. J Am Chem Soc 60:309-319

Cohen JM, Montiero JM (1991) Durability and integrity of marbles cladding: a state of the art review. J Perform Constr Facil $5(2): 113-124$

Dandekar DP (1968) Variation in the elastic constants of calcite with pressure. AGU Trans (Washington, DC) 49(1):323

Doehne E (2002) Salt weathering: a selective review. In: Siegesmund $\mathrm{S}$, Weiss $\mathrm{T}$, Vollbrecht A (eds) Natural stone, weathering phenomena, conservation strategies and case studies. Special Publications, vol 205. Geological Society, London, pp 51-64

Fassina V, Favaro M, Naccari A (2002) Principal decay patterns on Venetian monuments. In: Siegesmund S, Weiss T, Vollbrecht A (eds) Natural stone, weathering phenomena, conservation strategies and case studies. Special Publications, vol 205. Geological Society, London, pp 381-391

Grimm W (1999) Beobachtungen und Überlegengen zur Verformung von Marmorprojekten durch Gefügeauflockerung. Zeitschrift der Deutschen Geologischen Gesellschaft 150(2):195-236

Guyader J, Denis A (1986) Propagation des ondes dans les roches anisotropes sous constrainte evaluation de la qualite des schistes ardoisiers. Bull Eng Geol 33:49-55

Kessler DW (1919) Physical and chemical test of the commercial marbles of the United States. Technologic Papers of the Bureau of Standards, 123. Government Printing Office, Washington, DC

Kleber W (1959) Einführung in die Kristallographie. VEB Verlag Technik, Berlin

Koch A, Siegesmund S (2004) The combined effect of moisture and temperature on the anomalous expansion behaviour of marble. Environ Geol 46:350-363

Köhler W (1991) Untersuchungen zu Verwitterungsvorgängen an Carrara-Marmor in Potsdam-Sanssouci. In: Berichte zu Forschung und Praxis der Denkmalpflege in Deutschland, SteinschädenSteinkonservierung 2, pp 50-53

Kühnel RA (2000) Driving forces of rock degradation. Protection and conservation of the cultural heritage of the Mediterranean cities. In: Proceedings of the 5th international symposium on the conservation of monuments in the Mediterranean Basin, Seville, Spain, pp 7-9

Logan JM, Hadedt M, Lehnert D, Denton M (1993) A case if study of properties of marble as building veneer. Int J Rock Mech Min Sci Geomech 30:1531-1537 
Luque A, Cultrone G, Mosch S, Siegesmund S, Sebastian E, Leiss B (2009) Anisotropic behaviour of White Macael marble used in the Alhambra of Granada (Spain). The role of thermohydric expansion in stone durability. Eng Geol (available on line, 6 July 2009)

Malaga-Starzec K, Lindqvist JE, Schouenborg B (2002) Experimental study on the variation in porosity of marbles as a function of temperature. In: Siegesmund S, Weiss T, Vollbrecht A (eds) Natural stone, weathering phenomena, conservation strategies and case studies. Special Publications, vol 205. Geological Society, London, pp 81-88

Mingarro F (1996) Procesos de alteración. Degradación y conservación del Patrimonio Arquitectónico. Cursos de verano del Escorial, Complutense, pp 387-398

Passichier CW, Trouw RAJ (1996) Microtectonics. Springer, Berlin

Pérez Bernal JL, Bello López MA (2000) The fractal dimension of stone pore surface as weathering descriptor. Appl Surf Sci 161:47-53

Pérez Bernal JL, Bello López MA (2001) Fractal geometry and mercury porosimetry. Comparison and application of proposed models on buildings stones. Appl Surf Sci 185:99-107

Royer-Carfagni G (1999) Some considerations on the warping of marble facades: the example of Alvar Alto's Finlandia Hall in Helsinki. Constr Build Mater 13:449-457

Ruedrich J, Siegesmund S, Richter D (2001) Marble columns and their state of weathering: structural evidences and ultrasonic tomography. Z Dtsch Geol Ges 152:665-680

Ruiz-Agudo E, Luque A, Sebastián E, Rodríguez-Navarro C (2008) Changes in the pore structure of marble after salt decay tests. In: Libro de Actas del IX Congreso Internacional de Rehabilitación del Patrimonio Arquitectónico y Edificaciones, pp 147-150

Sáez-Pérez MP, Rodríguez-Gordillo J (2009) Structural and compositional anisotropy in Macael marble (Spain) by ultrasonic, XRD and optical microscopy methods. Constr Build Mater 23:21212126

Siegesmund S, Weiss T, Vollbrecht A, Ullemeyer K (1999) Marbles as a natural building stone: rock fabrics, physical and mechanical properties. Z dt Geol Ges 150/2 Stuttgart (Schweizerbart):237257

Siegesmund S, Ullermeyer K, Weiss T, Tschegg EK (2000) Physical weathering of marbles caused by anisotropic thermal expansion. Int J Earth Sci 89:170-182

Siegesmund S, Koch A, Ruedrich J (2007) Ursachen mangelnder Formbeständigkeit von Fassadenplatten: Fallstudie Universitätsbibliothek der Universität Göttingen. In: Siegesmund S, Ehling A (eds) Rohstoff Naturstein Teil 1. Z dt Ges Geowiss 158:630 648

Siegesmund S, Ruedrich J, Koch A (2008) Marble bowing: comparative studies of three different public building facades. Environ Geol 56:473-494
Siegesmund S, Kracke T, Ruedrich J, Schwarzburg R (2009) Jewish cemetery in Hamburg Altona (Germany): state of marble deterioration and provenance. Eng Geol (available on line, 22 July 2009)

Simon S, Snethlage R (1993) The first stages of marbles weathering, preliminary results after short-term exposure of nine month. Forschungs-Bericht (Eurocare-Euromarble EU 496), München (Bayrisches Landesamt für Denkmalpflege) 11:37-44

Tang P, Chew NYK, Chan H-K, Raper JA (2003) Limitation of determination of surface fractal dimension using $\mathrm{N}_{2}$ adsorption isotherms and modified Frenkel-Halsey-Hill theory. Langmuir 19:2632-2638

Thomasen SE, Ewart CS (1984) Durability of the thin-set marble. In: Third international conference on durability of building materials and components, pp 313-323

UNE-EN 1936:2007, Métodos de ensayo para piedra natural, Determinación de la densidad real, aparente, la porosidad abierta y total. AENOR

Weijermars R (1991) Geology and tectonics of the Betic Zone, SE Spain. Earth Sci Rev 31:153-236

Weiss T, Leiss B, Oppermann H, Siegesmund S (1999) Microfabric of fresh and weathered marbles: Implications and consequences for the reconstruction of the Marmopalais Postdam. Zeitschrift der Deutschen Geologischen Gesellschaft 152(2):313-332

Weiss T, Siegesmund S, Fuller ER (2002a) Thermal stresses and microcracking in calcite and dolomite marbles via finite element modelling. In: Siegesmund S, Weiss T, Vollbrecht A (eds) Natural stone, weathering phenomena, conservation strategies and case studies. Special Publications, vol 205. Geological Society, London, pp 65-80

Weiss T, Rasolofosaon PNJ, Siegesmund S (2002b) Ultrasonic wave velocities as a diagnostic tool for the quality assessment of marble. In: Siegesmund S, Weiss T, Vollbrecht A (eds) Natural stone, weathering phenomena, conservation strategies and case studies. Special Publications, vol 205. Geological Society, London, pp 149-164

Weiss T, Siegesmund S, Fuller ER (2003) Thermal degradation of marbles: indications from finite-element modelling. Build Environ 38:1251-1260

Winkler EM (1994) Stone in architecture. New York

Winkler EM (1996) Technical note: properties of marble as building veneer. Int J Rock Mech Min Sci Geomech 33:215-218

Xie H, Wang J, Qan P (1996) Fractal characters of micropore evolution in marbles. Phys Lett A 218:275-280

Zeisig A, Siegesmund S, Weiss T (2002) Thermal expansion and its control on the durability of marbles. In: Siegesmund S, Weiss T, Vollbrecht A (eds) Natural stone, weathering phenomena, conservation strategies and case studies. Special Publications, vol 205. Geological Society, London, pp 65-80 